\title{
Control of human hematopoietic stem/progenitor cell migration by the extracellular matrix protein Slit3
}

\author{
Sacha B Geutskens ${ }^{1}$, William D Andrews ${ }^{2}$, Anne-Marieke D van Stalborch ${ }^{1}$, Kim Brussen ${ }^{3}$, Sandra E Holtrop-de Haan ${ }^{1}$, \\ John G Parnavelas ${ }^{2}$, Peter L Hordijk ${ }^{1}$ and Paula B van Hennik ${ }^{1}$
}

Patients whose hematopoietic system is compromised by chemo- and/or radiotherapy require transplantation of hematopoietic stem and progenitor cells (HSPCs) to restore hematopoiesis. Successful homing of transplanted HSPCs to the bone marrow (BM) largely depends on their migratory potential, which is critically regulated by the chemokine CXCL12. In this study, we have investigated the expression and function of Slit proteins and their corresponding Roundabout (Robo) receptors in human HSPC migration. Slit proteins are extracellular matrix proteins that can modulate the (chemoattractant-induced) migration of mature leukocytes. We show that mRNAs for all Slits (Slit1-3) are expressed in primary BM stroma and BM-derived endothelial and stromal cell lines, but not in CD34 ${ }^{+}$HSPCs. Human CD34 ${ }^{+}$HSPCs expressed mRNAs for all Robos (Robo1-4), but only the Robo1 protein was detected on their cell surface. Functionally, Slit3 treatment increased the in vivo homing efficiency of CD34 ${ }^{+} \mathrm{HSPCs}$ to the BM in NOD/SCID mice, whereas Slit3-exposed HSPC migration in vitro was inhibited. These effects do not appear to result from modulated CXCL12 responsiveness as CXCR4 expression, CXCL12-induced actin polymerization or the basal and CXCL12-induced adhesion to fibronectin or BM-derived endothelial cells of CD34 ${ }^{+} \mathrm{HSPC}$ were not altered by Slit3 exposure. However, we show that Slit3 rapidly reduced the levels of active RhoA in $\mathrm{HL} 60$ cells and primary CD34 ${ }^{+} \mathrm{HSPC}$, directly affecting a pathway involved in actin cytoskeleton remodeling and HSPC migration. Together, our results support a role for Slit3 in human HSPC migration in vitro and homing in vivo and might contribute to the design of future approaches aimed at improving transplantation efficiency of human CD34 ${ }^{+}$HSPCs.

Laboratory Investigation (2012) 92, 1129-1139; doi:10.1038/labinvest.2012.81; published online 21 May 2012

KEYWORDS: adhesion; bone marrow; CXCL12; CXCR4; migration; robo; slit

Maintenance of hematopoietic stem cell (HSC) numbers is essential for long-term hematopoiesis. In adults, HSCs predominantly reside in the bone marrow (BM) cavity where they are found in close proximity to specialized stromal cells that create a specific microenvironment (ie, niche) facilitating HSC self-renewal and/or differentiation. ${ }^{1,2}$ Patients whose hematopoietic system is compromised by chemo- and/or radiotherapy require transplantation of HSCs to restore hematopoiesis. The intravenously administered HSCs traffic to the $\mathrm{BM}$, a process referred to as homing. In the $\mathrm{BM}$, the homed HSCs repopulate the niches to give rise to all mature blood cell lineages. HSC homing is crucial for effective hematological recovery and therapeutic regimes that enhance the migratory potential of HSCs may improve transplantation efficiency.
$\mathrm{BM}$ homing is a multi-step process that resembles the trafficking of mature leukocytes to sites of inflammation. Initial selectin-mediated tethering to and rolling of leukocytes over the endothelium is followed by integrin-mediated adhesion to the endothelial cell layer and subsequent transendothelial migration. ${ }^{3}$ This directional migration of leukocytes is primarily regulated by chemokines. The chemokine CXCL12 (or stromal cell-derived factor-1), which signals via the G-proteincoupled receptor CXCR4, promotes the integrin-mediated arrest of HSCs to the endothelium and induces HSC transmigration. ${ }^{4,5}$ CXCL12 can be regarded as the main chemoattractant for HSCs in vivo. ${ }^{6}$ and is produced by BM endothelial, BM stromal (BMS) cells ${ }^{4,7}$ and importantly, specialized niche cells such as CXCL12-producing reticular cells. ${ }^{8}$

\footnotetext{
'Department of Molecular Cell Biology, Sanquin Research and Landsteiner Laboratory, Academic Medical Center, University of Amsterdam, Amsterdam, The Netherlands; ${ }^{2}$ Department of Cell and Developmental Biology, University College London, London, UK and ${ }^{3}$ Department of Hematopoiesis, Sanquin Research and Landsteiner Laboratory, Academic Medical Center, University of Amsterdam, Amsterdam, The Netherlands

Correspondence: Dr SB Geutskens, PhD, Department of Immunohematology and Bloodtransfusion, Leiden University Medical Center, Room E3-50, Albinusdreef 2, 2333 ZA Leiden, The Netherlands.

E-mail: s.b.geutskens@lumc.nl

Received 1 August 2011; revised 11 March 2012; accepted 13 March 2012
} 
Slits are large matrix proteins that function as negative regulators of chemoattractant-induced leukocyte migration. ${ }^{9-11}$ Three highly homologous mammalian Slit proteins have been discovered ${ }^{12,13}$ that bind to receptors of the Roundabout (Robo) family through their second leucine-rich repeat domain. ${ }^{14,15}$ Robos are single-span transmembrane receptors that guide outgrowing neuronal axons during embryonic development. ${ }^{16}$ Thus far, four evolutionary conserved human Robo homologs have been identified that mainly differ in their intracellular cytoplasmic domains. ${ }^{16-19}$ The molecular mechanisms by which Slits mediate their effects on cell migration are not completely understood and possibly involves activation of members of the Rho family of small GTPases such as Rac1, Cdc42 and RhoA. We previously showed that Slit3 rapidly induces the activation of RhoA in $\mathrm{CD}_{14}{ }^{+}$human monocytes and promotes their migration. ${ }^{20}$ Slit3 functioned in a similar manner on endothelial cells, as was shown by Zhang et al. ${ }^{21}$ Monocytes express relatively low levels of Robol 1 as compared with $\mathrm{CD} 34^{+}$hematopoietic stem and progenitor cells (HSPCs), and we demonstrated that HSPCs reduce Robol expression upon their differentiation into monocytes. ${ }^{20}$

In this study, we further defined the Robo and Slit expression profile of circulating human $\mathrm{CD}_{3} 4^{+}$HSPCs and non-hematopoietic human $\mathrm{BM}$ cells and investigated the effect of human HSPC priming by Slit3 on in vitro and in vivo migration.

\section{MATERIALS AND METHODS Animals}

The 6-10-week-old NOD/LtSz-scid/scid (NOD/SCID) mice (Jackson Laboratory; Charles River, Maastricht, The Netherlands) were maintained under specific pathogen-free conditions in isolator cages and supplied with sterile food and acidified drinking water containing $100 \mathrm{mg} / \mathrm{l}$ ciprofloxacine ad libitum. Housing and care were in accordance with the institutional guidelines. Animal experiments were approved by the Animal Experiments Committee of the Netherlands Cancer Institute/Sanquin, Amsterdam, The Netherlands.

\section{Primary Human Cells}

$\mathrm{CD} 4^{+}$HSPCs were isolated from BM, cord blood (CB) and mobilized peripheral blood (MPB). Total BM cells were harvested from the iliac crest of healthy donors, CB samples were obtained from the Sanquin Cord Blood Bank (Leiden, The Netherlands), MPB samples were harvested from leukapheresis material of G-CSF-treated healthy donors $(2 \times 5 \mu \mathrm{g} / \mathrm{kg} /$ day subcutaneously; Filgrastim, Amgen, CA, USA) or a mantle cell lymphoma patient treated with chemotherapy and G-CSF. The samples were diluted in phosphate-buffered saline (PBS; Fresenius Kobi's Hertogenbosch, The Netherlands) with $2 \mathrm{mM}$ EDTA and $0.5 \% \mathrm{w} / \mathrm{v}$ bovine serum albumin (BSA; Sigma-Aldrich, Steinheim, Germany).

$\mathrm{CD}_{14}{ }^{+}$monocytes and $\mathrm{CD}^{+}{ }^{+} \mathrm{T}$ cells were harvested from peripheral blood of healthy donors by leukapheresis (Sanquin
Blood bank, Amsterdam, The Netherlands). Materials were diluted in PBS containing $4 \mathrm{~g} / \mathrm{l}$ pasteurized plasma protein (Sanquin Reagents, Amsterdam, The Netherlands) and 0.4\% sodium-citrate and subjected to separation with Ficoll-paque plus (Pharmacia Biotech, Upsala, Sweden) to collect mononuclear cells. $\mathrm{CD}_{3} 4^{+}, \mathrm{CD}^{+}$or $\mathrm{CD} 14^{+}$populations were obtained by magnetic cell sorting (Miltenyi Biotec, Bergisch Gladbach, Germany) reaching purities of $95 \%$ or more.

To obtain primary BMS cells, total BM cells were harvested from the iliac crest of healthy donors and plated in a culture flask (Nunc, Roskilde, Denmark) in Iscove's Modified Dulbecco's Medium (IMDM; Lonza, Verviers, Belgium) supplemented with $10 \%(\mathrm{v} / \mathrm{v})$ heat-inactivated fetal calf serum (FCS; Bodinco, Alkmaar, The Netherlands), $300 \mu \mathrm{g} / \mathrm{ml}$ glutamine, $100 \mathrm{U} / \mathrm{ml}$ penicillin and $100 \mathrm{U} / \mathrm{ml}$ streptomycin (all from Gibo-Invitrogen, Paisley, UK) and maintained at $37^{\circ} \mathrm{C}$, $5 \% \mathrm{CO}_{2}$. Hematopoietic cells were depleted by daily removal of the supernatant for the following week. The remaining adherent cells were cultured for an additional 2 weeks.

For in vitro-induced myeloid differentiation, HSPCs were cultured according to an adapted protocol of Olweus et al..$^{22}$ To this end, HSPCs were seeded in IMDM supplemented with $20 \%$ FCS, $100 \mathrm{ng} / \mathrm{ml}$ stem cell factor, $100 \mathrm{ng} / \mathrm{ml}$ interleukin-6; $10 \mathrm{ng} / \mathrm{ml}$ interleukin-3 (Strathman Biotech, Hamburg, Germany) and $20 \mathrm{ng} / \mathrm{ml}$ macrophage colonystimulating factor (Peprotech, London, UK). Myeloid differentiation was monitored using combinations of the following anti-human antibodies: CD34-APC (IQ-Products, Groningen, The Netherlands), CD33-PE (BD Biosciences, San Jose, CA, USA), CD14-PE (BD Biosciences and CD66b (Sanquin Reagents)).

All primary human material was obtained after informed consent and with approval of the Medical Ethical Committee of the Academic Medical Centre (Amsterdam, The Netherlands).

\section{Cell Lines}

HL60 and HEK293T cell lines were obtained from ATTC (Manassas, VA, USA). The human BM-derived stromal line L87/4 was described earlier. ${ }^{23}$ Cell lines were maintained at $37^{\circ} \mathrm{C}, 5 \% \mathrm{CO}_{2}$ in IMDM containing $10 \% \mathrm{v} / \mathrm{v}$ FCS, $300 \mu \mathrm{g} / \mathrm{ml}$ glutamine, $100 \mathrm{U} / \mathrm{ml}$ penicillin and $100 \mathrm{U} / \mathrm{ml}$ streptomycin. The BM-derived endothelial cell line (BMEC) $-28,{ }^{24}$ was maintained in EGM2 medium (Lonza) at $37^{\circ} \mathrm{C}, 5 \% \mathrm{CO}_{2}$.

\section{Reverse Transcription-PCR}

Total RNA was extracted using RNA-Bee reagent (Tel-test, Friendswood, TX, USA) and reverse transcribed with random hexamers and oligo(dT) primers using SuperScript III firststrand synthesis (Invitrogen, Carlsbad, CA, USA). Partial cDNAs of Slit or Robo homologs were amplified using specific primers (forward $5^{\prime}-3^{\prime}$, reverse $5^{\prime}-3^{\prime}$ ) as follows:

Slit1: 5'-ACGTGGTGCTTTTGATGACA, GCAAAACAGG TGGTTGGAGT- ${ }^{\prime}$;

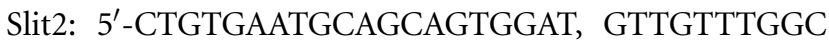
AAGCAGCATA-3'; 
Slit3: 5'-CCAGGATCACCAAGATGGAC, ATCCCCTGGAT CTGGTTTTC-3';

Robo1: 5'-CGGAGCCCGCTCACTTTTAC, TGCAGGTTC TCCTTTTGAGACA- $3^{\prime}$;

Robo2: 5'-CAACGATGCTCTCAGATGGA, GCATATGGG GTAGCCTGTGT-3';

Robo3: 5'-GCAGACCAAGCTTCCTGTC, CTCTCGGCGT TTCTGTCCT- $3^{\prime}$;

Robo4: 5'-GGGCTCTGGAGGAGACAG, CTGGGGGTGG ACTAGGATC-3';

and RT-PCR with Sybergreen reagent (Eurogentec, Maastricht, The Netherlands) and by using $\beta$-glucuronidase (GUS) as internal reference. ${ }^{25}$ Primer specificity was validated by checkerboard PCR using plasmids containing cDNA of the different Slits and Robos. ${ }^{26,27}$ Human umbilical vein endothelial cells cDNA was used as positive control for Robo3 and Robo4 expression. Slit expression in hematopoietic lineages was quantified by real-time PCR and measured with the ABI Prism 7700 Sequence Detection System and analyzed with the ABI Prism Sequence detector v1.6.3 software (Applied Biosystems, Foster City, CA, USA). Relative mRNA levels were quantified using the $\Delta$ CT method and normalized to GUS.

Analysis of Cell Surface Proteins Using Flow Cytometry Directly conjugated antibodies were used that recognize lineage markers specific for monocytes (anti-CD14-APC; BD Biosciences Pharmingen, San Diego, CA, USA), T lymphocytes (anti-CD3-FITC; BD Biosciences) or HSPCs (antiCD34-APC; IQ-Products). Surface expression of Robo homologs was examined using unconjugated antibodies recognizing Robol (Santa Cruz Biotechnology, Santa Cruz, CA, USA), Robo2, Robo3 or a nonspecific control (all obtained from R\&D systems, Minneapolis, MN, USA) combined with Alexa488- or Alexa647-conjugated secondary antibodies (Molecular Probes-Invitrogen, Leiden, The Netherlands). Robo4 expression was examined with a PE-conjugated antibody recognizing Robo4 (R\&D systems). Cell surface expression levels of CXCR4, CD45 and CD29 were examined using directly conjugated antibodies, ie, anti-CD184-PE (BD Biosciences), anti-CD45-PerCP (BD Biosciences) and CD29FITC (Sanquin Reagents), respectively. Purified human IgG $(10 \mu \mathrm{g} / \mathrm{ml})$ was used to block nonspecific binding. Mean fluorescence intensity (MFI) was measured using flow cytometry (FACSCanto, Becton Dickinson, Breda, The Netherlands).

\section{In Vitro Migration Assays}

Transwell migration assays were performed in Transwells of $6.5 \mathrm{~mm}$ diameter with $5-\mu \mathrm{m}$ pore size polycarbonate filters (Costar, Cambridge, MA, USA) coated with $10 \mu \mathrm{g} / \mathrm{ml}$ fibronectin (FN; Sigma-Aldrich). For transendothelial migration, BMEC-28 cells were cultured to confluence on FNcoated filters, stimulated with $10 \mathrm{ng} / \mathrm{ml}$ interleukin- $1 \beta$ (Strathman Biotech) for $4 \mathrm{~h}$, which was washed away before adding the HSPCs. Monolayer integrity was examined at the end of the experiment by filamentous actin staining of the monolayer using $5 \mu \mathrm{g} / \mathrm{ml}$ Alexa488-conjugated Phalloidin (Molecular Probes-Invitrogen (Life Technologies), Paisley, UK) and nuclear staining using Hoechst (Molecular probes). HL60 cells or HSPCs were incubated for $15 \mathrm{~min}$ at $37^{\circ} \mathrm{C}, 5 \%$ $\mathrm{CO}_{2}$ with conditioned medium, solvent $(\mathrm{PBS} / 0.1 \%(\mathrm{w} / \mathrm{v})$ BSA), recombinant murine $\mathrm{N}$-terminal Slit3 at the indicated concentrations and/or $12.5 \mu \mathrm{g} / \mathrm{ml}$ recombinant rat Robo1 Fc-chimera (R\&D Systems). A total of $1 \times 10^{5}$ cells $/ 100 \mu \mathrm{l}$ were added to the upper compartment and incubated for $4 \mathrm{~h}$ at $37^{\circ} \mathrm{C}, 5 \% \mathrm{CO}_{2}$ to migrate in the presence or absence of $100 \mathrm{ng} / \mathrm{ml}$ CXCL12 (Strathman Biotech) in the lower compartment. Migrated cells were quantified using flow cytometry and related to a fixed number of Cyto-Cal Count Beads (Duke Scientific, Palo Alto, CA, USA), which were added to the samples as internal reference. The percentage migrating cells was calculated using input controls. AnnexinV staining (Bender MedSystems GmbH, Vienna, Austria) was used to monitor cell viability upon Slit3 treatment.

\section{Human HSPC Homing}

MPB-derived CD34 ${ }^{+}$cells were incubated with solvent, 3.15 or $6.3 \mu \mathrm{g} / \mathrm{ml} \mathrm{Slit3}$ at $37^{\circ} \mathrm{C} / 5 \% \mathrm{CO} 2$ in migration medium for $2 \mathrm{~h}$, washed and resuspended in PBS containing the same Slit3 concentration. Next, human $\mathrm{CD} 34^{+}$cells $\left(1 \times 10^{6} /\right.$ mouse $)$ were injected into the lateral tail vein of 8-11-week-old male NOD/SCID mice that received a sublethal dose of 3.5 Gy total body irradiation $2 \mathrm{~h}$ before transplantation. HSPCs from two different MPB donors were used separately for each experiment, with five mice per experimental condition.

Twenty-two hours after transplantation, the number of human CD45/CD34-expressing cells was determined in the blood and cell suspensions of the spleen, liver, lungs and both femura. Quantification of the homed cells was performed as described earlier. ${ }^{28}$ Briefly, live cells were gated using the forward scatter/side scatter (SSC) plot, further gated into a CD34/SSC plot and subsequently analyzed using a CD34/ CD45 plot. Cell suspensions from untransplanted mice and isotype-specific control antibodies served as negative controls. The number of homed human cells was quantified using Cyto-Cal Count Beads as an internal quantification reference. The homing efficiency was defined as the percentage of the retrieved number of $\mathrm{CD} 34^{+} / \mathrm{CD} 45^{+}$cells from the total number of injected $\mathrm{CD} 34^{+} / \mathrm{CD} 45^{+}$cells.

\section{Human HSPC Engraftment}

Human HSPCs were infused as described for the homing experiments, except now $3 \times 10^{6} \mathrm{CD}^{+} 4^{+}$HSPCs were transplanted per mouse using CD $34^{+}$HSPC pooled from six MPB donors/ experiment. Mice were killed 35 days after transplantation and the blood, femora, spleen, liver and lungs were collected. Subsequently, the organs were processed into cell suspensions. The presence of human hematopoietic cell subsets was determined using combinations of the following anti-human antibodies: CD45-PerCP (BD Biosciences), 
CD34-APC (IQ-Products), CD38-FITC (Sanquin Reagents), CD33-PE (BD Biosciences), CD3-FITC (BD Biosciences), CD4-PE (BD Biosciences), CD19-FITC (Sanquin Reagents), CD20PE (BD Biosciences), CD16-FITC (Sanquin Reagents), CD56-PE (Sanquin Reagents), CD15-F (Sanquin Reagents) and CD14-PE (BD Biosciences). The percentage of live CD45 ${ }^{+}$ cells was used to determine the percentage of engraftment. Hematopoietic subsets are expressed as percentage of CD45. Results are depicted as mean \pm s.e.m.

\section{Static Adhesion Assay}

Adhesion assays were performed on FN-coated or BMECcoated 96-wells plates (Maxisorp; Nunc) blocked with PBS/ $1 \%(\mathrm{w} / \mathrm{v})$ BSA. Next, $3 \times 10^{5}$ solvent- or $15 \mathrm{~min}$ Slit3-treated Calcein AM (Molecular Probes-Invitrogen)-stained cells/ group were incubated for $30 \mathrm{~min}$ at $37^{\circ} \mathrm{C}$ with or without $100 \mathrm{ng} / \mathrm{ml}$ CXCL12. Non-adherent cells were removed and input controls were added to separate wells. Cells were lyzed with $\mathrm{PBS} / 0.1 \%(\mathrm{v} / \mathrm{v})$ Triton and fluorescence intensity was quantified using a Tecan GENios plate reader (Tecan, Mannedorf, Switzerland). The percentage of adherent cells was calculated by dividing fluorescence intensity measured in the experimental wells by that of the corresponding input control.

\section{Actin Polymerization Assay}

Cells were suspended in migration medium at $1 \times 10^{6}$ cells/ $\mathrm{ml}$ and starved for $30 \mathrm{~min}$ at $37^{\circ} \mathrm{C}$ and $5 \% \mathrm{CO}_{2}$. Solvent or $3.15 \mu \mathrm{g} / \mathrm{ml}$ Slit3-treated cells were stimulated with $100 \mathrm{ng} / \mathrm{ml}$ CXCL12 at $0,30,60,120$ or $300 \mathrm{~s}$ while maintained at $37^{\circ} \mathrm{C}$. Cells were fixed and permeabilized using the IntraPrep Permeabilization kit (Immunotech S.A., Marseille, France). Polymerized actin was visualized by staining the cells with $5 \mu \mathrm{g} / \mathrm{ml}$ Alexa488-conjugated Phalloidin (Molecular Probes). The MFI was measured using flow cytometry.

\section{Immunoblotting of (Phospho-)Proteins}

For the analysis of phosphorylated proteins, $1.4 \times 10^{6}$ or $3.0 \times 10^{6} \mathrm{CD}^{4} 4^{+}$HSPCs were treated for $5 \mathrm{~min}$ with or without 3.15 or $6.3 \mu \mathrm{g} \mathrm{Slit} 3 / \mathrm{ml}$ and/or for $5 \mathrm{~min}$ with $100 \mathrm{ng} / \mathrm{ml} \mathrm{CXCL12.} \mathrm{Cells} \mathrm{were} \mathrm{lysed} \mathrm{in} 10 \mathrm{mM}$ Tris, $50 \mathrm{mM}$ $\mathrm{NaCl}, 1 \%$ Triton-X100, $30 \mathrm{mM} \mathrm{NP}_{2} \mathrm{O}_{7}, 50 \mathrm{mM} \mathrm{NaF}, 100 \mu \mathrm{m}$ $\mathrm{Na}_{3} \mathrm{VO}_{4}, 1 \mathrm{mM}$ DTT, $0.5 \mu \mathrm{m}$ phenylmethylsulfonylfluoride, $5 \mathrm{nM}$ okadaic acid and EDTA-free protease inhibitor cocktail (Roche, Woerden, The Netherlands). Proteins were separated on $4-12 \%$ Precast Nupage gels (Invitrogen), transferred to PVDF membrane (Bio-Rad, Hercules, CA, USA) and analyzed by immunoblotting using antibodies recognizing phosphorylated tyrosine residues (Santa Cruz), total Akt (Cell Signalling Technology, Danvers, MA, USA), phosphorylated Akt (Cell Signaling Technology), total ERK1/2 (Santa Cruz), phosphorylated ERK2 (Santa Cruz), total PAK (Becton Dickinson), phosphorylated PAK (Invitrogen), total p38 (Cell Signalling Technology), and phosphorylated p38 (Santa Cruz). Primary antibodies were detected by perox- idase-conjugated (Dako Cytomation, Glostrup, Denmark), IRDye 680-conjugated or IRDye 800-conjugated secondary antibodies (LI-COR Biosciences, Lincoln, NE, USA). Fluorescent protein signal was detected using the Odyssey Infrared Imaging System (LI-COR Biosciences) and analyzed with the Odyssey V3.0 software (LI-COR).

Expression of green fluorescent protein (GFP)-tagged Slit3 was determined in total 293T-lysates after separating proteins by electrophoresis in 3-8\% gradient Precast Nupage tris (hydroxymethal) aminomethane (Tris)-Acetate gels (Invitrogen). Proteins were transferred to nitrocellulose blots (Whatman GmbH, Dassel, Germany) and Slit3-GFP was visualized a GFP-recognizing antibody (JL-8; Clontech Laboratories, St-Germain-en-Laye, France) followed by incubation with a peroxidase-conjugated secondary antibody (Dako Cytomation). Peroxidase activity was visualized with super ECL (Thermoscientific, Rockford, IL, USA) on X-ray films (Fuji Films, Tokyo, Japan).

\section{RhoA Activity Assay}

The level of active RhoA was determined using an ELISAbased assay, ie, the RhoA G-LISA ${ }^{\mathrm{TM}}$ (Cytoskeleton, Denver, CO, USA). In brief, $2 \times 10^{6}$ HL60 cells or $1 \times 10^{6} \mathrm{MPB}-$ derived CD34 ${ }^{+}$HSPCs were incubated at $37^{\circ} \mathrm{C}$ with Slit3 (at a concentration of $10 \mu \mathrm{g} / \mathrm{ml}$ or $5 \mu \mathrm{g} / \mathrm{ml}$, respectively) or equal volume of solvent (ie, PBS supplemented with $1 \mathrm{M}$ $\mathrm{NaCl}$ and $0.1 \% \mathrm{w} / \mathrm{v} \mathrm{BSA}$ ) at the indicated time points. Slit3 priming was stopped on ice, immediately followed by cold centrifugation. The cell pellet was lysed in ice-cold lysis buffer and incubated on ice for $1 \mathrm{~min}$. Membrane fragments were removed by centrifugation and the clear lysate was further processed according to the manufacturers' instructions. Absorbance was measured at $485 \mathrm{~nm}$ using a Tecan GEnios Plus plate reader (Tecan) and Magellan V6.5 software (Tecan).

\section{Statistic Analysis}

Two-tailed Student's $t$-test was used to determine statistical significant differences. Results with a $P$-value $<0.05$ were considered significantly different.

\section{RESULTS \\ Slit Proteins are Expressed by Cells from the BM niche, Whereas Human CD34 ${ }^{+}$HSPCs Express Robo}

We first investigated whether Slit and Robo homologs are expressed in the human BM, ie, in non-hematopoietic BM cells such as endothelial and stromal cells, which are found in close proximity to $\mathrm{CD} 34^{+}$HSPC. Using RT-PCR, we readily detected expression of Slit 1, -2 and -3 in primary BMS and in the BM-derived stromal (L87/4) and BMEC-28 cell lines (Figure 1a). Quantification of the levels of Slit mRNA using real-time RT-PCR revealed that the level of Slit1 mRNA in mature leukocytes was comparable to that of the BMS cell line, L87/4. Expression of Slit2 and -3 mRNA was not 

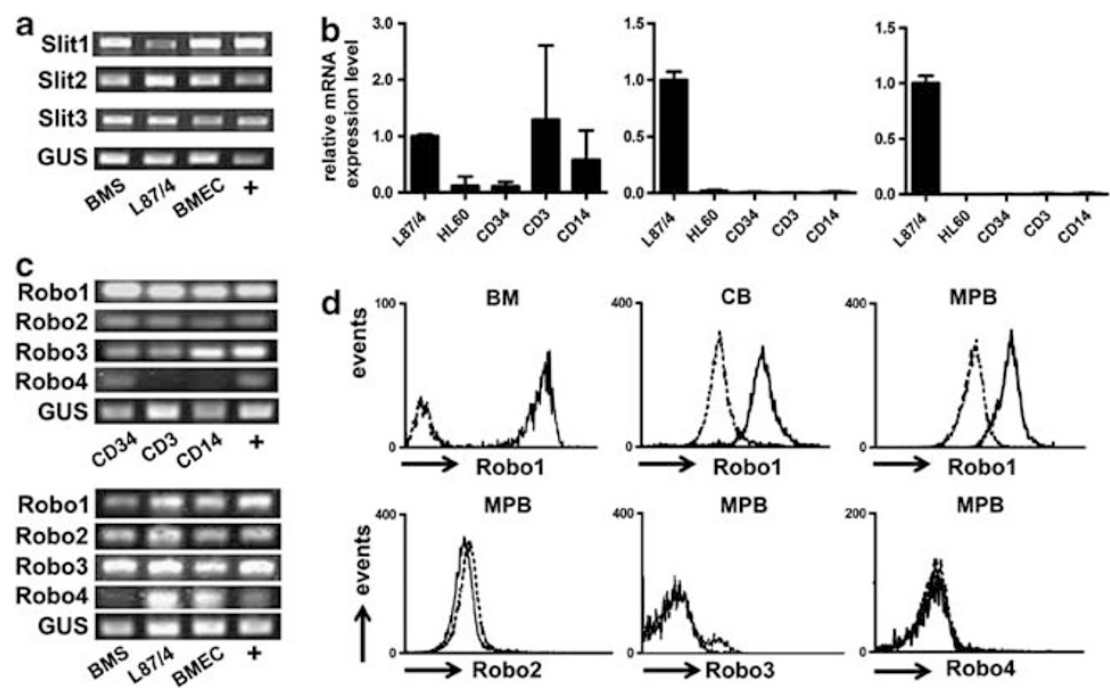

Figure 1 Roundabout (Robo) and Slit expression by hematopoietic and bone marrow (BM) niche cells. (a) Slit1-3 mRNA expression in BM niche cells, ie, primary BM stromal (BMS), the L87/4 BMS cell line and BM-derived endothelial cell line (BMEC). (b) Slit mRNA levels in hematopoietic cells normalized to $\beta$ glucuronidase (GUS) and relative to L87/4 levels. (c) Robo1-4 mRNA expression in hematopoietic and BM niche cells. (d) Cell surface Robo1 expression of $\mathrm{CD}_{4}{ }^{+}$cells (bold line: specific antibody recognizing the indicated Robo homologue; dotted line: isotype control antibody). A representative donor out of three or more donors is shown. (d) Cell surface expression of Robo2, Robo3 and Robo4 on mobilized peripheral blood (MPB)-derived CD34 + cells (bold line: specific antibody recognizing the indicated Robo homologue; dotted line: isotype control antibody). A representative donor out of three or more donors is shown).

detected in any of the hematopoietic cell types, and none of the Slits could be detected in CD34 ${ }^{+}$cells (Figure 1b). Expression of Robo1, -2 and -3 mRNA was readily detectable in all hematopoietic and non-hematopoietic cells examined (Figure 1c), whereas expression of Robo4 mRNA was detected in L87/4 cells, BMEC-28 cells and CD34 ${ }^{+}$HSPCs. To confirm whether mRNA expression correlated to protein expression, we examined surface protein expression of Robo1-4 using Robo-homologue-specific antibodies (Supplementary Figure 1) in a flow cytometric approach. Human CD34 ${ }^{+}$HSPCs from different sources, ie, BM, CB and MPB, all express Robol on their cell surface (Figure 1d). However, cell surface expression of the other Robo proteins was hardly detected on MPBderived $\mathrm{CD} 34^{+}$cells (Figure 1e).

Thus, mRNAs for all Slit ligands are expressed by BMderived stromal and endothelial cells, whereas Robol is the main receptor for Slit that is expressed by human $\mathrm{CD} 34^{+}$ HSPCs.

\section{Slit3 Inhibits CXCL12-Induced and Spontaneous Migration of $\mathrm{CD}_{4}{ }^{+}$HSPC}

As human HSPCs express the Robol receptor that recognizes Slit proteins, we investigated whether treatment with Slit affected HSPC migration in vitro. Slit2 was previously shown to inhibit CXCL12-induced chemotaxis of the Robo1-positive promyelocytic HL60 leukemic cell line. ${ }^{11}$ Here, the effect of commercially available purified recombinant $\mathrm{N}$-terminal Slit3 (Slit3) on HL60 cells was examined at concentrations that were previously shown to inhibit GABAergic interneuron proliferation ${ }^{29}$ or to promote human monocyte migration. ${ }^{20}$ Figure 2a shows that the CXCL12-induced migration of HL60 cells pre-incubated with Slit3 was inhibited in a dose-dependent manner. Similar results were obtained when HEK293T-conditioned medium enriched for the complete human GFP-tagged Slit3 protein was used (Supplementary Figure 2).

Next, we examined whether exposure to Slit3 affected primary human $\mathrm{CD} 34^{+}$HSPC migration in vitro. Slit3 did not affect the CXCL12-induced migration of CD34 ${ }^{+}$HSPCs derived from three healthy MPB and three CB donors, using concentrations that induced maximal inhibition of HL60 migration $(12.5 \mu \mathrm{g} / \mathrm{ml}$; Figure $2 \mathrm{~b})$. However, lower Slit3 concentrations did reduce the CXCL12-induced migration of MPB-derived CD34 ${ }^{+}$HSPCs in five out of six donors (mean percentage of inhibition ( \pm s.d.) ranging from $20.9 \pm 2.5 \%$ (MPB donor 7) at $6.3 \mu \mathrm{g} / \mathrm{ml}$ Slit3 to $58.0 \pm 6.9 \%$ inhibition (MPB donor 6) at $3.15 \mu \mathrm{g} / \mathrm{ml}$ Slit3; Figure 2c). Slit concentrations $<3.15 \mu \mathrm{g} / \mathrm{ml}$ do not appear to be effective (Supplementary Figure 3A). Interestingly, Slit3 also affected the spontaneous migration (without CXCL12 being present) of MPB-derived CD34 ${ }^{+}$HSPCs of most donors (Figure 2c), except for MPB donor 8 that was refractory to Slit-mediated effects. The response induced by Slit3 appears to be dosedependent and possibly follows a bell-shaped curve that is also typical for chemoattractants. ${ }^{30}$ Importantly, the specificity of the Slit3-induced response was confirmed by the addition of soluble extracellular Robol (Robo1Fc), which abolished Slit3-mediated inhibition of CD34 ${ }^{+}$HSPC chemotaxis (Figure 2d). Evaluation of all donors together showed that both effective Slit3 dosages significantly 
inhibited the CXCL12-induced HSPC migration $(n=9$; $P<0.05$ for $3.15 \mu \mathrm{g} / \mathrm{ml}$ Slit3 and $6.3 \mu \mathrm{g} / \mathrm{ml}$ Slit3 using a paired $t$-test).
Thus, Slit3 inhibits spontaneous and CXCL12-induced migration of CD34 ${ }^{+}$HSPCs over FN-coated Transwell filters in a dose- and donor-dependent manner.
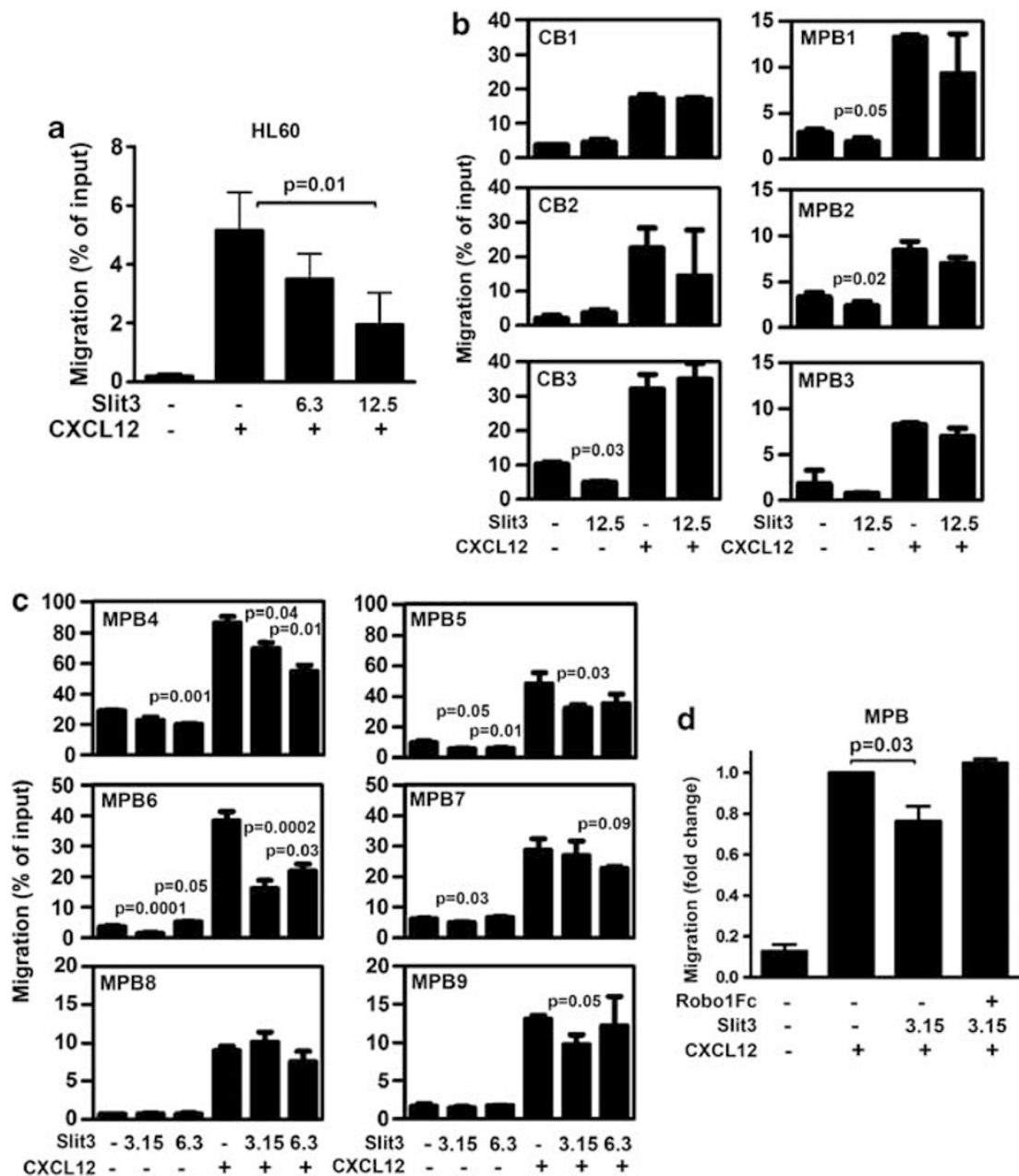

Figure 2 Slit3 inhibits migration of $\mathrm{CD}_{3}{ }^{+}$hematopoietic stem and progenitor cells (HSPCs) in vitro. (a) Transwell migration of HL60 cells treated with 6.3 or $12.5 \mu \mathrm{g} / \mathrm{ml}$ purified Slit3 (Slit3) in the presence or absence of $100 \mathrm{ng} / \mathrm{ml} \mathrm{CXCL12} \mathrm{in} \mathrm{the} \mathrm{lower} \mathrm{compartment.} \mathrm{Experiments} \mathrm{were} \mathrm{performed} \mathrm{in}$ triplicate and presented as mean \pm s.d. Data show a representative example of two experiments. (b) Transwell migration of cord blood (CB)- or mobilized peripheral blood (MPB)-derived CD34 ${ }^{+}$cells treated with solvent or $12.5 \mu \mathrm{g} / \mathrm{ml}$ Slit3 in the presence or absence of $100 \mathrm{ng} / \mathrm{ml} \mathrm{CXCL12} \mathrm{in} \mathrm{the} \mathrm{lower}$ compartment. Experiments were performed per donor in triplicate and presented as mean \pm s.d. (c) Migration of MPB-derived-CD34 ${ }^{+}$cells treated with solvent, 3.15 or $6.3 \mu \mathrm{g} / \mathrm{ml}$ Slit3 toward migration medium or $100 \mathrm{ng} / \mathrm{ml} \mathrm{CXCL12.} \mathrm{Experiments} \mathrm{were} \mathrm{performed} \mathrm{per} \mathrm{donor} \mathrm{in} \mathrm{triplicate} \mathrm{and} \mathrm{presented} \mathrm{as}$ mean \pm s.d. (d) Migration of human IgG or Roundabout (Robo) 1Fc pre-incubated MPB-derived CD34 ${ }^{+}$HSPCs (mean \pm s.e.m.; $n=3$ ). Data represent the fold

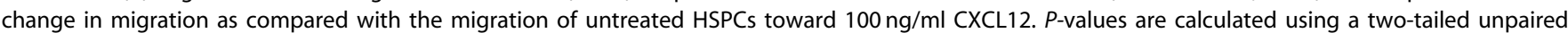
Student's $t$-test.

Figure 3 Slit3 enhances $\mathrm{CD}_{4} 4^{+}$hematopoietic stem and progenitor cell (HSPC) homing. (a) Live cells gated in R1 (forward scatter (FSC)/side scatter (SSC): left dot plot) were shown in a SSC/CD34 dot plot and the SSC ${ }^{l o} C D 34$ hi - expressing cells were gated in R2 and shown in a CD34/CD45 dot plot. The human (hu)CD34 ${ }^{+} / \mathrm{CD} 5^{+}$cells were gated and quantified in R3. Beads acquired in R4 were used for quantification. Representative dot plots are depicted showing bone marrow (BM) cell suspensions from a mouse that did not receive human cells (irradiation/staining control), a mouse that received untreated human HSPCs and a mouse that received HSPCs treated with $3.15 \mu \mathrm{g} / \mathrm{ml}$ Slit3, respectively. (b) Bar graphs showing the mean percentage of HSPCs ( \pm s.e.m.) that homed to total BM (open bars) or spleen (filled bars) of five mice per experimental condition for two separate donors. $P$-values are calculated using an unpaired Student's $t$-test. (c) Mean percentage of human $\mathrm{CD} 45^{+}$cells in the blood, BM and spleen of NOD/SCID mice $(n=5 /$ experimental condition), 5 weeks after transplantation of $\mathrm{CD}_{3} 4^{+} \mathrm{HSPCs}$ treated with solvent, $3.15 \mu \mathrm{g} / \mathrm{ml} \mathrm{Slit3} \mathrm{or} 6.3 \mu \mathrm{g} / \mathrm{ml}$ Slit3. A representative experiment out of two separate experiments is shown. $P$-values are calculated using an unpaired Student's $t$-test. (d) The left graph shows in vitro myeloid differentiation of CD34 ${ }^{+}$ HSPCs treated with solvent or $6.3 \mu \mathrm{g} / \mathrm{ml}$ Slit3. The stacked bar graph shows the percentage of CD34 ${ }^{+} \mathrm{CD}_{3} 3^{-}$cells (dotted bars), CD34 ${ }^{+} \mathrm{CD} 33^{+}$cells (open bars), $\mathrm{CD}_{3} 4^{-} \mathrm{CD} 33^{+}$cells (dashed bars), $\mathrm{CD} 14^{+}$monocytes (vertical dashed bars) and CD66b ${ }^{+}$granulocytes (filled bars) at 3,6 and 9 days of culture. Data of a representative experiment out of two separate experiments are shown. The bar graph on the right shows the absolute cell number (mean \pm s.d.) during in vitro myeloid differentiation of two different donors treated with solvent (open bars) or $6.3 \mu \mathrm{g} / \mathrm{ml}$ Slit3 (filled bars). 
Slit3 Enhances Homing of HSPC to the BM of NOD/SCID Mice

Migration is an important feature of HSPC recruitment to the BM (homing). To determine the effect of Slit3 on HSPC homing, the murine NOD/SCID xenogenic transplantation model was used. Migration of CD34 ${ }^{+}$HSPCs pre-exposed to Slit3 was still reduced after washing (Supplementary Figure 3B). For homing assays human CD $34^{+}$HSPCs, either

a

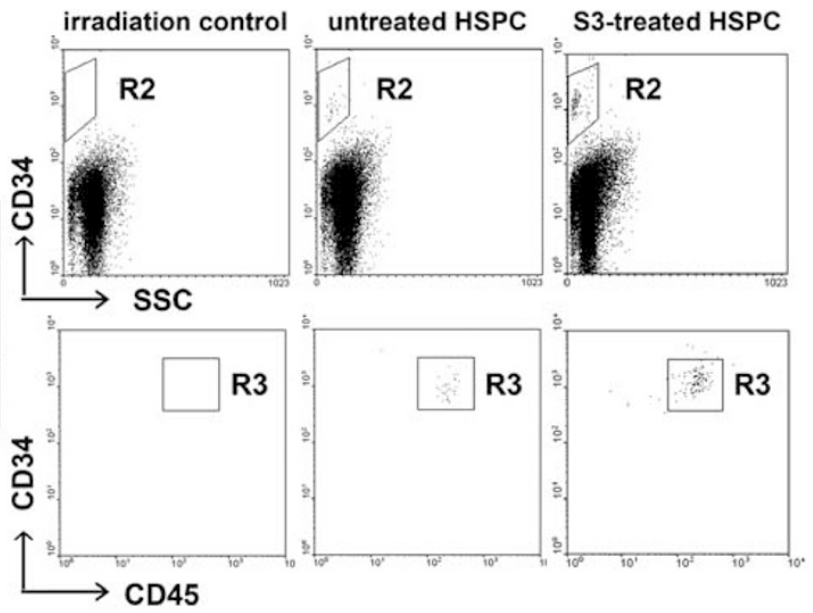

b BM
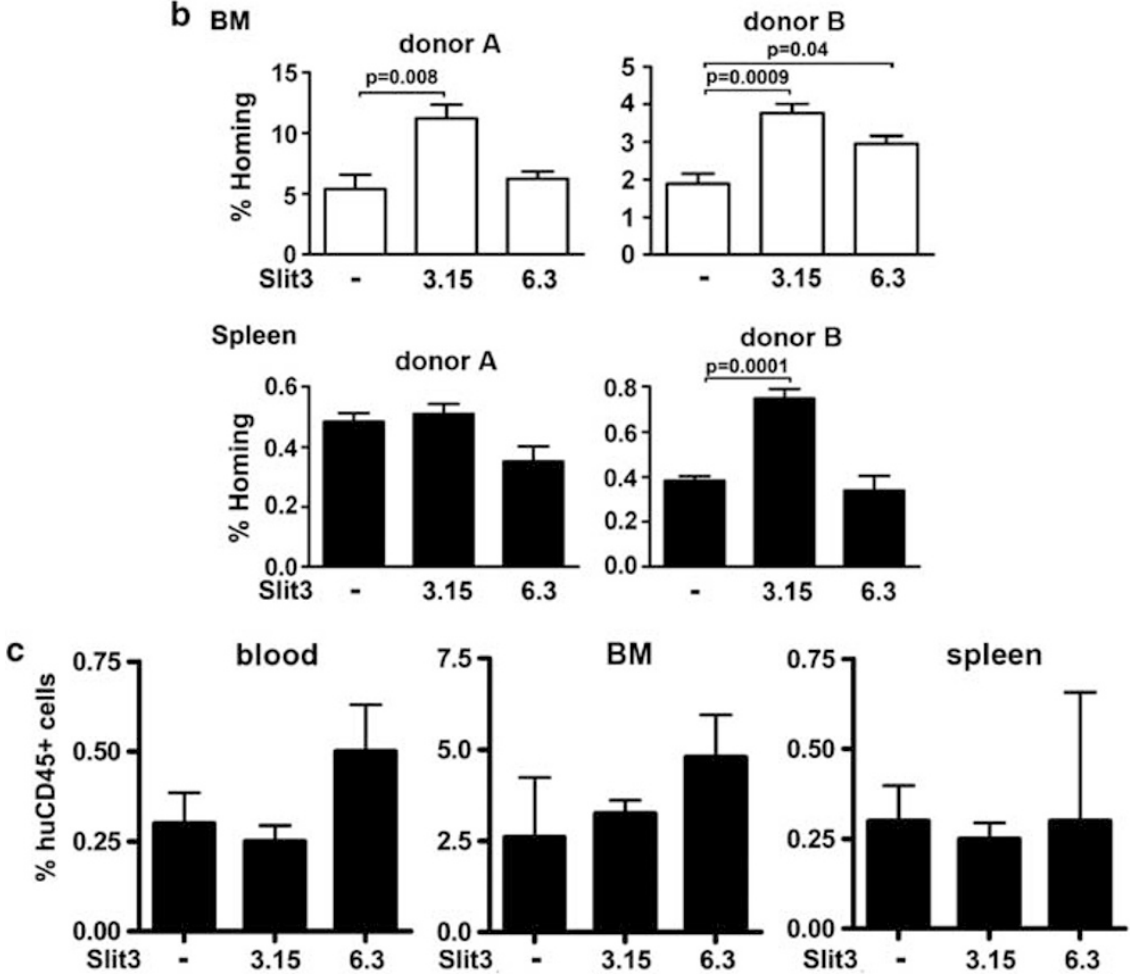

d
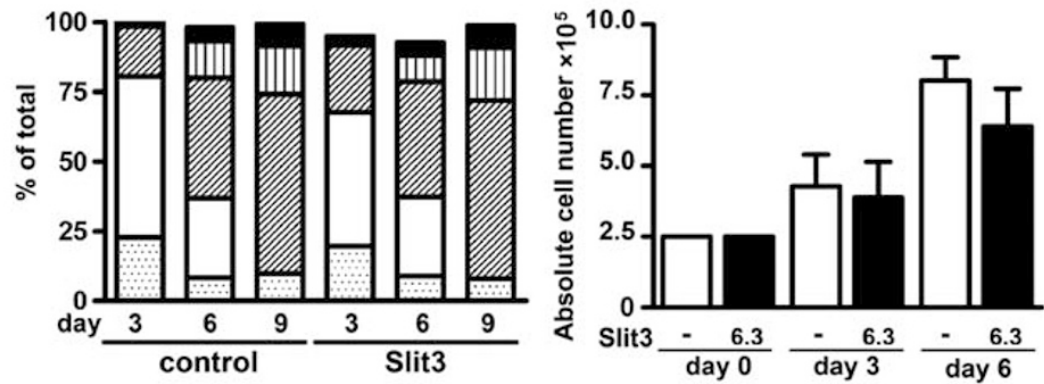
pre-exposed to solvent or Slit3 were transfused intravenously and the percentage of human $\mathrm{CD} 34^{+} / \mathrm{CD} 45^{+}$HSPCs that had homed to the BM or other organs was determined at $22 \mathrm{~h}$ after infusion. $\mathrm{CD} 34^{+} / \mathrm{CD} 45^{+}$human HSPCs were readily detected in the BM (Figure 3a) and spleen, but were absent in the blood and liver (data not shown). Interestingly, a twofold higher percentage of Slit3-treated HSPCs had homed to the BM as compared with untreated HSPCs and these results were confirmed in a second experiment using a different MPB donor (Figure 3b). Thus, in contrast to the inhibitory effect observed in vitro, Slit3 enhanced the homing of HSPCs to the BM of NOD/SCID mice.

Increased BM homing may augment the transplantation efficiency as measured by the capacity of HSPCs to generate hematopoietic progeny upon BM colonization. To determine whether Slit3 affected the engraftment potential of HSPCs, Slit3-pre-treated HSPCs were transplanted into NOD/SCID mice and the percentage of mature hematopoietic human $\mathrm{CD} 45^{+}$cells was determined in the blood, BM, spleen, liver and lungs at 5 weeks after transplantation. Corresponding with the increased homing, a clear trend toward increased BM engraftment of Slit3-pre-treated human HSPC was observed as measured by the number of $\mathrm{CD} 45^{+}$cells detected in the blood and BM (Figure 3c).

Engraftment does not solely depend on homing but also on the proliferation and differentiation capacity of the homed HSPCs. We therefore additionally examined whether Slit3 affects myeloid differentiation of human $\mathrm{CD} 34^{+} \mathrm{HSPC}$ in vitro using an adapted protocol of Olweus et al. ${ }^{22}$ After 3 days in culture most HSPCs lost expression of surface CD34, but gained expression of surface CD33, which is characteristic for myeloid differentiation (Figure 3d). Surface expression of the monocyte-associated molecule CD14 and granulocyte-associated CD66b by CD33 ${ }^{+}$cells was observed after 6 days. No significant differences were found in percentages or absolute cell counts of $\mathrm{CD} 34^{+} / \mathrm{CD} 33^{-}, \mathrm{CD} 33^{+} / \mathrm{CD} 34^{-}, \mathrm{CD} 33^{+} / \mathrm{CD} 34^{+}$, $\mathrm{CD} 4^{+}$or $\mathrm{CD} 6 \mathrm{~b}^{+}$cells between solvent- or Slit3-treated HSPCs during in vitro culture (Figure $3 \mathrm{~d}$ ). Based on these in vitro experiments, Slit3 does not appear to affect HSPC survival or their capacity for myeloid differentiation under these conditions.

\section{Slit3 Did Not Affect the Adhesion of HSPCs to or Transendothelial Migration over BMEC}

For efficient homing in vivo, intravenously administered HSPCs need to adhere and transmigrate through the BM endothelium. As opposite effects of Slit3 were observed for HSPC migration in vitro and in vivo, we examined the effects of Slit3 on transmigration of HSPCs over BMEC-28 monolayers. Pre-treatment of HSPCs with Slit3 did not alter the number of HSPCs migrating over BMEC-28 monolayers in response to CXCL12 (mean migration percentage \pm s.e.m. $(n=3)$, of $5.4 \pm 0.7 \%$ for untreated, $6.2 \pm 0.7 \%$ for $3.15 \mu \mathrm{g} /$ $\mathrm{ml} \mathrm{Slit3-treated} \mathrm{and} 5.7 \pm 0.5 \%$ for $6.3 \mu \mathrm{g} / \mathrm{ml}$ Slit3-treated HSPC, respectively; Figure 4a). Furthermore, exposure of HSPCs to Slit3 did not significantly alter the basal or CXCL12induced adhesion of HSPCs to FN (Figure 4b), did not induce
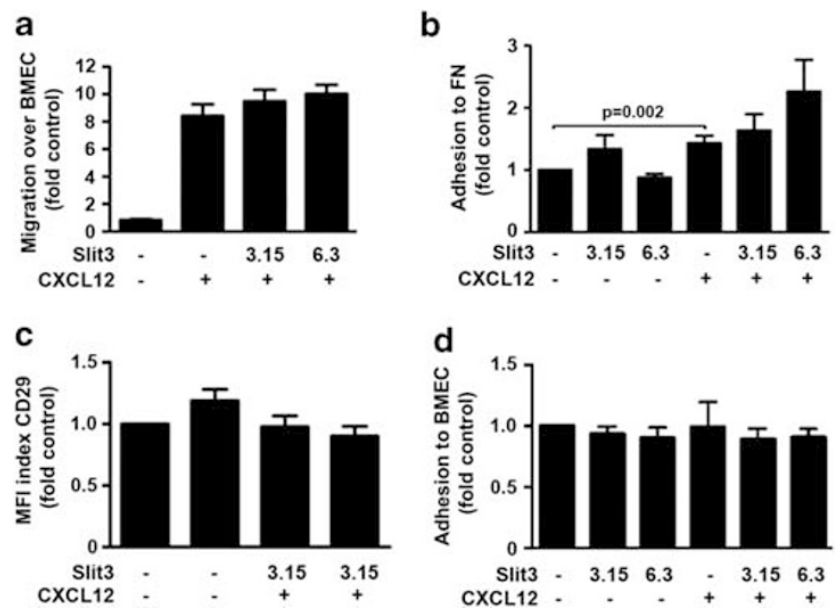

Figure 4 Slit3 does not alter transendothelial migration or hematopoietic stem and progenitor cell (HSPC) adhesion to FN or BM-derived endothelial cell line (BMEC). (a) BMEC-28-transmigrating mobilized peripheral blood (MPB)-derived $\mathrm{CD}_{34}{ }^{+}$cells. Fold change in migration relative to the control (mean \pm s.e.m.; $n=3$ ). (b) MPB-derived $\mathrm{CD}_{3} 4^{+}$cells adherent to FN-coated surfaces (c). Surface expression of CD29 of MPB-derived CD34 ${ }^{+}$cells depicted as fold change mean fluorescence intensity (MFI) ( \pm s.e.m.) relative to solvent-treated cells $(n=3)$. (d) MPB-derived CD34 ${ }^{+}$cells adherent to BMEC-coated surfaces, as in (b) the mean fold change in adhesion ( \pm s.e.m.) of three different donors (FN adhesion) or five different donors (BMEC adhesion) relative to solvent-treated cells is depicted.

detectable changes in surface levels of $\beta 1$-integrin (CD29; Figure 4c) nor did Slit3 alter the basal or CXCL12-induced adhesion of HSPCs to BMEC (Figure 4d). Together this suggests that Slit3 does not affect the cellular machinery required for transendothelial migration or the effect of Slit3 is counteracted by the interaction of HSPCs with BM-derived endothelial cells.

\section{The Effect of Slit3 is not Mediated Through Modulation of CXCL12 Responsiveness}

To further investigate the mechanism by which Slit3 affects HSPC migration, we examined whether exposure of HSPCs to Slit3 modulates CXCL12 responsiveness. CXCL12 responses are mediated by its receptor CXCR4, and the extent of CXCL12-mediated internalization of CXCR4 correlates with CXCL12-induced responsiveness and chemotaxis. ${ }^{31}$ Pre-incubation of HSPCs with Slit3 did not affect basal cell surface expression levels of CXCR4, CD34 or CD45, whereas exposure to CXCL12 did reduce the surface expression levels of CXCR4 as expected (Figure 5a). Interestingly, exposure to CXCL12 reduced the expression level of Robol on HSPCs by $16.0 \pm 10.6 \%$ (mean \pm s.e.m.), which significantly decreased even further $(27.9 \pm 5.5 \%)$ when CXCL12 stimulation was preceded by incubation of the HSPCs with Slit3 (Figure 5a), suggesting that CXCL12/CXCR4 signaling can negatively regulate cell surface expression of Robol. We next examined if exposure of CD34 ${ }^{+}$HSPCs to Slit3 modulated CXCL12induced actin polymerization (Figure 5b), CXCL12-induced calcium flux (not shown) or HSPC morphology (not shown), but none of these parameters were affected. Together, these 
a

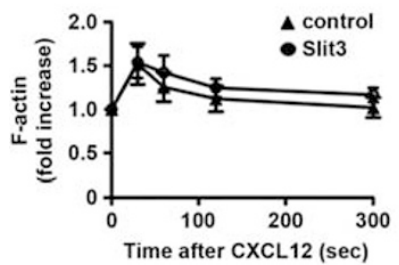

b

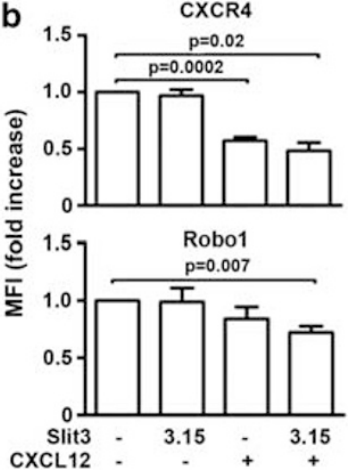

CD34

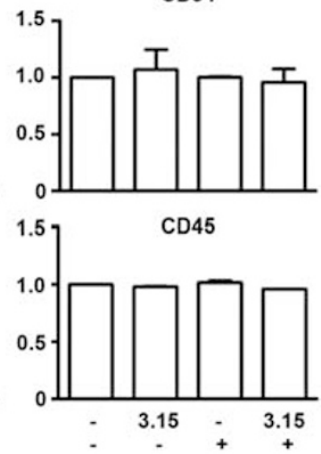

Figure 5 Slit3 does not alter CXCR4 signaling. (a) Mobilized peripheral blood (MPB)-derived CD34 ${ }^{+}$cells treated for 10 min with solvent (triangles) or $3.15 \mu \mathrm{g} / \mathrm{ml}$ Slit3 (circles), mean fold increase ( \pm s.e.m.) in polymerized actin $(n=3)$. $P$-values are calculated using a two-tailed unpaired Student's $t$-test. (b) Surface expression of CXCR4, Roundabout (Robo) 1, CD34 or CD45 of MPB-derived CD34 ${ }^{+}$cells shown as mean mean fluorescence intensity (MFI) ( \pm s.e.m.) relative to solvent-treated cells $(n=3)$.

data indicate that it is unlikely that altered HSPC migration after exposure to Slit3 is the result of reduced responsiveness to CXCL12.

\section{Slit3 Reduces the Levels of Active RhoA in Human HSPCs}

In addition to CXCL12-induced migration, Slit3 also reduced the spontaneous migration of HSPCs in vitro. We therefore investigated whether Slit3 initiates intracellular signaling events by itself. Slit3 indeed induced intracellular signaling, as is demonstrated by the phosphorylation of tyrosine residues of proteins corresponding to molecular weights between $65-95$ and $36-55 \mathrm{kDa}$ upon treatment of primary CD34 ${ }^{+}$ HSPCs with different concentrations of Slit3 (Figure 6a). Activation of proteins within these size regions that are important for cell migration such as Akt, PAK and mitogenactivated protein kinases (MAPK) p38 and pERK $^{32-34}$ were subsequently examined. To this end, primary CD $34^{+}$HSPCs were treated with solvent, CXCL12 and/or Slit3. As is shown in Figure 6b, PAK phosphorylation is increased in response to CXCL12, but no changes in basal or CXCL12-induced levels of phosphorylated PAK were observed upon Slit3 treatment. Levels of phosphorylated AKT, p38 and p42/p44 MAPK were very low, and an increase in phosphorylation was only observed after pervanadate treatment of human CD34 ${ }^{+}$HSPCs. Overall, these data do not suggest that Akt, PAK, p38 or ERK1/2 are involved in the Slit3-induced responses of HSPCs.

In human monocytes Slit3 rapidly activated RhoA and enhanced monocyte migration. ${ }^{20}$ We examined the effects of Slit3 priming on the levels of active RhoA in HL60 cells and primary human $\mathrm{CD} 34^{+}$HSPCs. In contrast to the Slit3 effects previously observed for human monocytes, levels of active RhoA were rapidly reduced in HL60 cells as compared with solvent-treated cells (Figure 6c), with a maximal reduction at $2 \mathrm{~min}(P=0.03$ Mean \pm s.e.m., $n=3)$. Slit3 similarly reduced the levels of active RhoA in $\mathrm{CD} 34^{+}$HSPCs with a maximal reduction at $5 \mathrm{~min}$ after the addition of Slit3. As with the migratory response, considerable donor heterogeneity was observed (Figure 6d).
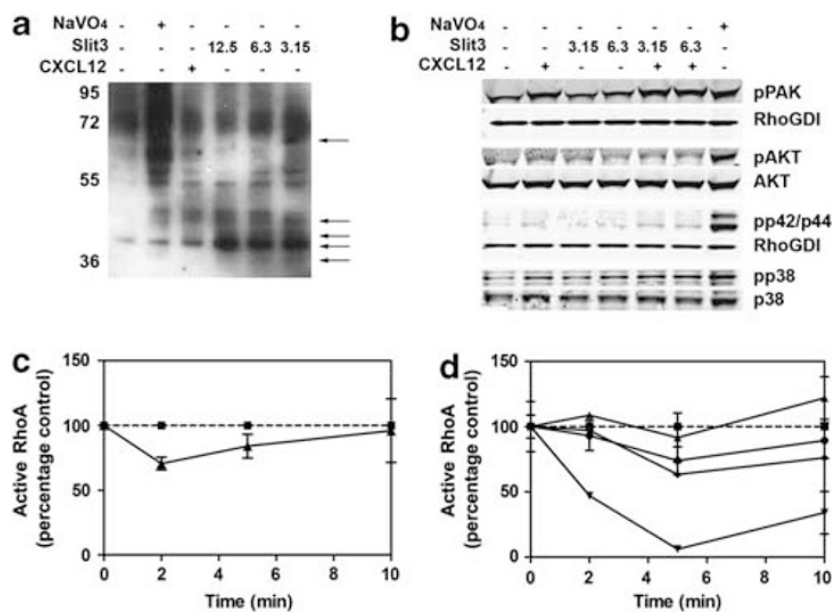

Figure 6 Slit3 reduces the levels of active RhoA in human HL60 cells and primary hematopoietic stem and progenitor cells (HSPCs). (a) Immunoblot stained for tyrosine-phosphorylated proteins of primary CD34 ${ }^{+} \mathrm{HSPC}$ lysates. Pervanadate was used as a positive control. Slit3-induced phosphorylation is indicated with arrows. (b) Immunoblots of primary CD34 ${ }^{+}$HSPC lysates stained for different downstream effectors of CXCL12. RhoGDI ( $\sim 28 \mathrm{kDa}$ ) was used as a loading control. Representative blots of an individual $\mathrm{CD} 34^{+}$HSPC donor out of two or more donors are shown. (c) The graph depicts the percentage (mean \pm s.e.m., $n=3$ ) of active RhoA in Slit3-treated HL60 cells ( $10 \mu \mathrm{g} / \mathrm{ml}$ Slit3, solid line) relative to solvent-treated cells at each time-point (dashed line). (d) The percentage of active RhoA in Slit3-treated CD34 ${ }^{+}$HSPCs ( $5 \mu \mathrm{g} / \mathrm{ml}$ Slit3) isolated from four different donors (solid lines) relative to solvent-treated cells at each time point (dashed line).

Thus, Slit3 treatment directly affects an essential pathway for HSPC migration by rapidly decreasing RhoA activity.

\section{DISCUSSION}

CD34 ${ }^{+}$HSPC transplantation is used to restore hematopoiesis in patients whose hematopoietic system is compromised by chemo- and/or radiotherapy. This study was initiated to investigate novel therapeutic regimes that may enhance the migratory potential of human CD $34^{+}$HSPCs, with the final aim to improve transplantation efficiency. Slits 
were recently described as powerful chemorepellents that either inhibit or promote chemokine-induced migration of mature leukocytes. ${ }^{9-11}$ This study is the first to report effects of Slit3 pretreatment on human CD34 ${ }^{+}$HSPC migration. We here show that all Slit homologs are expressed by human primary BMS, BM-derived endothelial and stromal cells, but not by human HSPCs. Conversely, mRNAs for all Robo homologs were detected in human $\mathrm{CD}_{3} 4^{+} \mathrm{HSPC}$ and we confirmed the cell surface expression of Robol protein. Noteworthy is the expression of Robo4 mRNA in HSPCs, but not in the other hematopoietic lineages. Robo4 was considered to be endothelial-specific, but previously found to be expressed by long-term repopulating murine HSCs. ${ }^{35}$ Moreover, a functional role in BM retention of murine cKit + Lin-Scal + HSCs was recently attributed to Robo4 using a Robo4 knockout mouse model, ${ }^{36}$ we were unable to detect cell surface Robo4 expression on the human $\mathrm{CD} 34^{+}$HSPCs populations examined, which possibly reflects the low frequency of immature HSCs present in the CD34-selected HSPC population.

Both Robo1 and Robo4 proteins bind Slit3 protein, ${ }^{21}$ and we show here that priming of Robol-expressing human $\mathrm{CD}^{+} 4^{+}$HSPCs with Slit3 significantly increased HSPC homing to the BM of NOD/SCID mice. In addition, a clear trend toward enhanced BM engraftment of Slit3-treated HSPC was observed. This difference did not reach statistical significance, which might be explained by the use of six different MPB donors required to obtain sufficient HSPC numbers for transplantation. The donor variability that was observed in the Slit 3 response may even out and conceal a marked effect on HSPC engraftment.

Contrary to the enhanced HSPC homing in vivo, an inhibitory effect of Slit3 treatment was observed on the (CXCL12-induced) migration of human $\mathrm{CD}^{+} 4^{+}$HSPCs in vitro. Contrasting effects of in vitro migration versus in vivo homing have been reported earlier by Kollet et $a l^{37}$ and Fukuda et al, ${ }^{38}$ who showed reduced in vitro migration capacity of HSPCs toward CXCL12, while BM homing was enhanced. It is difficult to identify the underlying cause that accounts for the diffferent outcomes, given the multi-factorial nature of in vivo migration. Chalasani et $a l^{39}$ showed that CXCL12 may antagonize Slit function by reducing the responsiveness of retinal ganglion cells to Slit. BMderived cells might be producing CXCL12 at levels that counteract the Slit3-induced response. Moreover, we observed that CXCL12 diminishes expression of surface Robol, an effect that is even more evident upon prior incubation of HSPCs with Slit3. This may indicate a possible feedback mechanism via the CXCL12/CXCR4 axis that counteracts Slit-induced responses in HSPCs relevant for their homing to, and retention within the BM. CXCL12 responsiveness is a major determinant for efficient homing, ${ }^{6}$ but other stimuli received from the microenvironment, such as cytokines and growth factors, may significantly affect the homing response of HSPCs. ${ }^{40}$ In different cellular models it has indeed been demonstrated that Slit-induced responses can be modulated by microenvironmental signals encountered in vivo, such as heparan sulfate proteoglycans, ${ }^{41}$ cyclic nucleotides ${ }^{42}$ or bone morphogenetic protein antagonists $^{9}$ that alter or reverse the Slit-induced response from repulsion into attraction. ${ }^{43}$ Thus, signaling pathways activated in vivo may function as a molecular switch of the Slit3-induced response and modify the migratory behavior of transplanted Slit3-pretreated HSPCs.

The molecular mechanisms by which Slit 3 exerts its effects are largely unknown. Slit was initially described to counteract CXCR4-mediated signaling events in hematopoietic cells. ${ }^{10,11}$ Our results suggest that Slit3 does not exclusively interfere with chemoattractant-induced signaling, but affects HSPC migration in a more general manner. We previously found that Slit3 rapidly induced the activation of RhoA in primary human monocytes and promoted monocyte migration. ${ }^{20}$ Slit3 similarly increased RhoA activity and motility in Robol/ Robo4-expressing endothelial cells. ${ }^{21}$ Small RhoGTPases such as Rac, Cdc42 and RhoA are important regulators of the actin cytoskeleton and are critically involved in regulating HSPC homing. ${ }^{44}$ We show here that Slit3 inhibits both CXCL12induced and spontaneous HSPC migration of Slit-responsive donors. Exposure of HSPCs to Slit3 increased the phosphorylation levels of tyrosine residues of several proteins within the 65-95- and $36-55-\mathrm{kDa}$ range. Moreover, we demonstrate that Slit3 reduces the levels of active RhoA in HL60 cells and primary CD34 ${ }^{+}$HSPCs. Active RhoA is required for the proper migration of human $\mathrm{HSPC}^{45}$ and monocytes ${ }^{46}$ and destabilizes the microtubule structure at the rear pole. Intriguingly, Ghiaur et $a l^{47}$ showed that reduced RhoA activity in murine HSCs resulted in reduced CXCL12induced migration in vitro, but enhanced BM engraftment. Unfortunately, HSC homing was not addressed separately in this study. Dissecting the exact signaling events induced by Slits will be of significant value to understand how Slit3 exerts its effect on migration and will aid the development of future approaches aimed at improving the transplantation efficiency of human CD $34^{+}$HSPCs.

Supplementary Information accompanies the paper on the Laboratory Investigation website (http://www.laboratoryinvestigation.org)

\section{ACKNOWLEDGEMENTS}

We thank the people from the animal facility and stem cell laboratory of Sanquin, Dr JG Geng for helpful discussions and Dr JJ Bajramovic, Dr C Voermans and $\operatorname{Dr} M$ von Lindern for critically reading this manuscript. This work was financially supported by the Sanquin Research PPO-C 03-007 (S.B.G) and a NWO Veni-grant (916.56.077) to PBH.

\section{DISCLOSURE/CONFLICT OF INTEREST}

The authors declare no conflict of interest.

1. Calvi LM, Adams GB, Weibrecht KW, et al. Osteoblastic cells regulate the haematopoietic stem cell niche. Nature 2003;425:841-846.

2. Zhang J, Niu C, Ye L, et al. Identification of the haematopoietic stem cell niche and control of the niche size. Nature 2003;425:836-841.

3. Springer TA. Traffic signals for lymphocyte recirculation and leukocyte emigration: the multistep paradigm. Cell 1994;76:301-314. 
4. Aiuti A, Webb IJ, Bleul C, et al. The chemokine SDF-1 is a chemoattractant for human $\mathrm{CD} 34+$ hematopoietic progenitor cells and provides a new mechanism to explain the mobilization of CD34+ progenitors to peripheral blood. J Exp Med 1997;185:111-120.

5. Peled $\mathrm{A}$, Kollet $\mathrm{O}$, Ponomaryov $\mathrm{T}$, et al. The chemokine SDF-1 activates the integrins LFA-1, VLA-4, and VLA-5 on immature human CD34(+) cells: role in transendothelial/stromal migration and engraftment of NOD/SCID mice. Blood 2000;95:3289-3296.

6. Peled A, Petit I, Kollet $O$, et al. Dependence of human stem cell engraftment and repopulation of NOD/SCID mice on CXCR4. Science 1999;283:845-848.

7. Dar A, Goichberg P, Shinder V, et al. Chemokine receptor CXCR4dependent internalization and resecretion of functional chemokine SDF-1 by bone marrow endothelial and stromal cells. Nat Immunol 2005;6:1038-1046.

8. Omatsu $\mathrm{Y}$, Sugiyama $\mathrm{T}$, Kohara $\mathrm{H}$, et al. The essential functions of adipo-osteogenic progenitors as the hematopoietic stem and progenitor cell niche. Immunity 2010;33:387-399.

9. Chen B, Blair DG, Plisov $S$, et al. Cutting edge: bone morphogenetic protein antagonists Drm/Gremlin and Dan interact with Slits and act as negative regulators of monocyte chemotaxis. J Immunol 2004 173:5914-5917.

10. Prasad A, Qamri Z, Wu J, et al. Slit-2/Robo-1 modulates the CXCL12/ CXCR4-induced chemotaxis of T cells. J Leukoc Biol 2007;82:465-476.

11. Wu JY, Feng L, Park HT, et al. The neuronal repellent Slit inhibits leukocyte chemotaxis induced by chemotactic factors. Nature 2001 410:948-952.

12. Brose $\mathrm{K}$, Bland KS, Wang $\mathrm{KH}$, et al. Slit proteins bind Robo receptors and have an evolutionarily conserved role in repulsive axon guidance. Cell 1999;96:795-806.

13. Yuan W, Zhou L, Chen JH, et al. The mouse SLIT family: secreted ligands for $\mathrm{ROBO}$ expressed in patterns that suggest a role in morphogenesis and axon guidance. Dev Biol 1999:212:290-306.

14. Kidd T, Bland KS, Goodman CS. Slit is the midline repellent for the robo receptor in Drosophila. Cell 1999;96:785-794.

15. Chen JH, Wen L, Dupuis $\mathrm{S}$, et al. The $\mathrm{N}$-terminal leucine-rich regions in Slit are sufficient to repel olfactory bulb axons and subventricular zone neurons. J Neurosci 2001;21:1548-1556.

16. Kidd T, Brose $\mathrm{K}$, Mitchell KJ, et al. Roundabout controls axon crossing of the CNS midline and defines a novel subfamily of evolutionarily conserved guidance receptors. Cell 1998;92:205-215.

17. Huminiecki $L$, Gorn $M$, Suchting $S$, et al. Magic roundabout is a new member of the roundabout receptor family that is endothelial specific and expressed at sites of active angiogenesis. Genomics 2002;79:547-552.

18. Simpson $\mathrm{JH}$, Kidd $\mathrm{T}$, Bland $\mathrm{KS}$, et al. Short-range and long-range guidance by slit and its Robo receptors. Robo and Robo2 play distinct roles in midline guidance. Neuron 2000;28:753-766.

19. Yuan SS, Cox LA, Dasika GK, et al. Cloning and functional studies of a novel gene aberrantly expressed in RB-deficient embryos. Dev Biol 1999;207:62-75.

20. Geutskens SB, Hordijk PL, van Hennik PB. The chemorepellent Slit3 promotes monocyte migration. J Immunol 2010;185:7691-7698.

21. Zhang B, Dietrich UM, Geng JG, et al. Repulsive axon guidance molecule Slit3 is a novel angiogenic factor. Blood 2009.

22. Olweus J, Lund-Johansen F, Terstappen LW. CD64/Fc gamma RI is a granulo-monocytic lineage marker on CD34+ hematopoietic progenitor cells. Blood 1995;85:2402-2413.

23. Thalmeier $K$, Meissner $P$, Reisbach $G$, et al. Establishment of two permanent human bone marrow stromal cell lines with long-term post irradiation feeder capacity. Blood 1994;83:1799-1807.

24. Rood PM, Calafat J, dem Borne $A E$, et al. Immortalisation of human bone marrow endothelial cells: characterisation of new cell lines. Eur J Clin Invest 2000;30:618-629.

25. Beillard E, Pallisgaard N, van der Velden $\mathrm{VH}$, et al. Evaluation of candidate control genes for diagnosis and residual disease detection in leukemic patients using 'real-time' quantitative reverse-transcriptase polymerase chain reaction (RQ-PCR) - a Europe against cancer program. Leukemia 2003;17:2474-2486.
26. Liu Z, Patel K, Schmidt $\mathrm{H}$, et al. Extracellular Ig domains 1 and 2 of Robo are important for ligand (Slit) binding. Mol Cell Neurosci 2004;26:232-240.

27. Patel $K$, Nash JA, Itoh $A$, et al. Slit proteins are not dominant chemorepellents for olfactory tract and spinal motor axons. Development 2001;128:5031-5037.

28. van Hennik PB, de Koning AE, Ploemacher RE. Seeding efficiency of primitive human hematopoietic cells in nonobese diabetic/severe combined immune deficiency mice: implications for stem cell frequency assessment. Blood 1999;94:3055-3061.

29. Andrews W, Barber M, Hernadez-Miranda LR, et al. The role of Slit-Robo signaling in the generation, migration and morphological differentiation of cortical interneurons. Dev Biol 2008;313:648-658.

30. Poznansky MC, Olszak IT, Foxall R, et al. Active movement of $T$ cells away from a chemokine. Nat Med 2000;6:543-548.

31. Shen $\mathrm{H}$, Cheng T, Olszak I, et al. CXCR-4 desensitization is associated with tissue localization of hemopoietic progenitor cells. J Immunol 2001;166:5027-5033.

32. Rousseau $\mathrm{S}$, Dolado I, Beardmore V, et al. CXCL12 and C5a trigger cell migration via a PAK1/2-p38alpha MAPK-MAPKAP-K2-HSP27 pathway. Cell Signal 2006;18:1897-1905.

33. Arai A, Jin A, Yan W, et al. SDF-1 synergistically enhances IL-3-induced activation of the Raf-1/MEK/Erk signaling pathway through activation of Rac and its effector Pak kinases to promote hematopoiesis and chemotaxis. Cell Signal 2005;17:497-506.

34. Peng SB, Peek V, Zhai $Y$, et al. Akt activation, but not extracellular signal-regulated kinase activation, is required for SDF-1alpha/CXCR4mediated migration of epitheloid carcinoma cells. Mol Cancer Res 2005;3:227-236.

35. Shibata F, Goto-Koshino Y, Morikawa Y, et al. Roundabout 4 is expressed on hematopoietic stem cells and potentially involved in the niche-mediated regulation of the side population phenotype. Stem Cells 2009;27:183-190.

36. Smith-Berdan $S$, Nguyen A, Hassanein D, et al. Robo4 cooperates with CXCR4 to specify hematopoietic stem cell localization to bone marrow niches. Cell Stem Cell 2011;8:72-83.

37. Kollet $\mathrm{O}$, Spiegel A, Peled A, et al. Rapid and efficient homing of human CD34(+)CD38(-/low)CXCR4(+) stem and progenitor cells to the bone marrow and spleen of NOD/SCID and NOD/SCID/B2m(null) mice. Blood 2001;97:3283-3291.

38. Fukuda $\mathrm{S}$, Bian $\mathrm{H}$, King AG, et al. The chemokine GRObeta mobilizes early hematopoietic stem cells characterized by enhanced homing and engraftment. Blood 2007;110:860-869.

39. Chalasani SH, Sabol A, Xu H, et al. Stromal cell-derivedfactor-1 antagonizes slit/robo signaling in vivo. J Neurosci 2007;27:973-980.

40. Bonig H, Priestley GV, Papayannopoulou T. Hierarchy of molecularpathway usage in bone marrow homing and its shift by cytokines. Blood 2006;107:79-86.

41. Hu H. Cell-surface heparan sulfate is involved in the repulsive guidance activities of Slit2 protein. Nat Neurosci 2001;4:695-701.

42. Nguyen-Ba-Charvet KT, Brose K, Marillat V, et al. Sensory axon response to substrate-bound Slit2 is modulated by laminin and cyclic GMP. Mol Cell Neurosci 2001;17:1048-1058.

43. Kramer SG, Kidd T, Simpson JH, et al. Switching repulsion to attraction: changing responses to slit during transition in mesoderm migration. Science 2001:292:737-740.

44. Cancelas JA, Jansen M, Williams DA. The role of chemokine activation of Rac GTPases in hematopoietic stem cell marrow homing, retention, and peripheral mobilization. Exp Hematol 2006;34:976-985.

45. Fonseca AV, Freund D, Bornhauser M, et al. Polarization and migration of hematopoietic stem and progenitor cells rely on the RhoA/ROCK I pathway and an active reorganization of the microtubule network. J Biol Chem 2010;285:31661-31671.

46. Worthylake RA, Lemoine $S$, Watson $J M$, et al. RhoA is required for monocyte tail retraction during transendothelial migration. J Cell Biol 2001;154:147-160.

47. Ghiaur G, Lee A, Bailey J, et al. Inhibition of RhoA GTPase activity enhances hematopoietic stem and progenitor cell proliferation and engraftment. Blood 2006;108:2087-2094. 